\title{
Subtypes of intestinal metaplasia and Helicobacter pylori
}

\author{
M E Craanen, P Blok, W Dekker, J Ferwerda, G N J Tytgat
}

\begin{abstract}
To determine whether there is a relationship between the presence of $\boldsymbol{H}$ pylori and the various subtypes of intestinal metaplasia in the gastric antrum, 2274 antral gastroscopic biopsies from 533 patients were examined. H pylori was found in 289 patients. Intestinal metaplasia in general was found in 135 patients. Type I intestinal metaplasia was found in 133 patients $(98.5 \%)$, type II in 106 patients $(78 \cdot 5 \%)$ and type III in 21 patients $(15 \cdot 6 \%)$. Ninety eight of these 135 patients $(72.6 \%)$ were $H$ pylori positive and 37 patients $(27.4 \%)$ were $\boldsymbol{H}$ pylori negative. No statistically significant difference was found in the prevalence of type I and II intestinal metaplasia between the intestinal metaplasia positive and $H$ pylori positive and intestinal metaplasia negative and $\boldsymbol{H}$ pylori negative patients. Type III intestinal metaplasia was found less often in the intestinal metaplasia positive and $\boldsymbol{H}$ pylori positive patients $(11 \cdot 2 \%)$ as compared with intestinal metaplasia positive and $\boldsymbol{H}$ pylori negative patients $(27 \%)(p<0.05)$. In contrast with type I and II intestinal metaplasia type III intestinal metaplasia was found more often in moderate/ severe intestinal metaplasia than in mild intestinal metaplasia $(\mathbf{p}<0.02)$. Within the group of patients with moderate/severe intestinal metaplasia, type III was found less often in the $H$ pylori positive patients $(\mathbf{p}<0.05)$. We suggest that the gastric milieu for $H$ pylori is less appropriate in type III intestinal metaplasia positive patients. As type III intestinal metaplasia might be regarded as a marker of possibly increased gastric cancer risk, the lower prevalence of $\boldsymbol{H}$ pylori in these type III intestinal metaplasia positive patients might be the result of severe changes in mucosal architecture.
\end{abstract}

There is overwhelming evidence that infection with Helicobacter pylori causes chronic active gastritis, which invariably involves the gastric antrum. ${ }^{1-3}$ Although acute gastritis has been described in volunteers after ingestion of $H$ pylori, ${ }^{45}$ this condition is rarely encountered and biopsied in routine clinical practice. Eradication of $H$ pylori may lead to rapid reversion of the histological abnormalities found in $H$ pylori related gastritis. ${ }^{36}$ Failure to eradicate $H$ pylori totally, however, yields only temporary improvement of the histological picture. This, in turn, may eventually lead to the progression of chronic active gastritis to chronic gastritis with a variable degree of atrophy.

Chronic atrophic gastritis and its accompany- ing lesion, intestinal metaplasia are widely recognised as being the most prevalent precursors of intestinal type gastric carcinoma.? Subtypes of intestinal metaplasia have been identified based upon histological, ultrastructural, enzyme, and mucin histochemical characteristics. Some of the latter studies have suggested that a sulphomucin secreting, incomplete intestinal metaplasia subtype is particularly closely linked to intestinal type gastric carcinoma and may therefore be a marker of increased gastric cancer risk. ${ }^{8-13}$ In another study evidence was found for a strong association between the presence of intestinal metaplasia in general and $H$ pylori in the gastric antral mucosa. ${ }^{14} \mathrm{We}$ undertook this study in order to investigate further the relationship between the presence of $H$ pylori and the various subtypes of intestinal metaplasia in the gastric antral mucosa.

\section{Patients}

\section{METHODS}

All patients were referred to the St Elisabeth's of Groote Gasthuis on clinical grounds for upper gastrointestinal endoscopy between December 1988 and June 1990. Endoscopy was carried out after an overnight fast. The endoscopes (Olympus GIF Q10,Q20) were cleaned with detergent, disinfected with $70 \%$ ethanol and rinsed with sterile water after each examination. Patients requiring emergency endoscopy or with previous gastric surgery were excluded.

Patients with antral abnormalities, varying from mild erythema of the mucosa to full blown endoscopic gastritis, gastric ulcer and carcinoma were included. The number of antral biopsies taken depended on the diagnosis made by the endoscopists. Biopsies were taken at $3 \mathrm{~cm}$ from the pylorus in mild erythema of the antral mucosa and in cases where there was severe endoscopic erythematous/exudative gastritis with or without erosions. Where gastric ulcer and carcinoma were present, biopsies were taken from the lesions and from the adjacent mucosa within $1 \mathrm{~cm}$ of the lesions along the lesser and greater curvature within $4 \mathrm{~cm}$ from the pylorus. All biopsies were fixed in $10 \%$ formalin, embedded in paraffin and cut at $5 \mu \mathrm{m}$. Routine staining with haematoxylin and eosin $(\mathrm{H} \& \mathrm{E})$ was performed for histopathologic diagnosis and detection of $H$ pylori. Where it was doubtful whether $H$ pylori was present, additional Giemsa staining was carried out. $H$ pylori was judged to be absent where both staining methods were negative for $H$ pylori.

The extent of intestinal metaplasia as well as 
the prevalence of its subtypes was assessed independently by two of the authors (MC/PB). The extent of distribution of intestinal metaplasia was graded as follows: (1) none (-); (2) mild degree $(+)$, consisting of a few tubules to one third of the total area biopsied; (3) moderate degree $(++)$, consisting of one third to two thirds of the total area biopsied; (4) severe degree $(+++)$; consisting of two thirds or more of the total area biopsied. Biopsies showing intestinal metaplasia were serially sectioned and stained with: (1) alcian blue $\mathrm{pH} 2 \cdot 5 /$ periodic acid-Schiff (AB pH 2.5/PAS); (2) high iron diamine/alcian blue $\mathrm{pH} 2.5$ (HID/AB $\mathrm{pH} 2.5)$ in order to identify subtypes of intestinal metaplasia. ${ }^{15} 16$ Subtypes of intestinal metaplasia were classified as described by Filipe. ${ }^{17}$

Type I intestinal metaplasia is characterised by the presence of goblet cells secreting acid sialomucins and sometimes sulphomucins, Paneth cells and mature, non-mucous secreting, absorptive cells. Type II is characterised by the presence of goblet cells secreting sialomucins and sometimes sulphomucins, almost complete absence of Paneth cells and replacement of absorptive cells by columnar mucous cells secreting non-sulphated mucins, and type III resembles type II intestinal metaplasia in most respects but the columnar mucous cells secrete predominantly sulphomucins.

\section{STATISTICAL ANALYSIS}

The $\chi^{2}$ correct test and two tailed Student's $t$ test were used in the statistical analysis of the data collected when appropriate.

\section{Results}

A total of 2274 biopsies was examined from 533 patients. Intestinal metaplasia was found in 135 patients $(25 \cdot 3 \%)$ and $H$ pylori was found in

TABLE I Characteristics of patients according to histological diagnosis $(\mathrm{n}=533)$

\begin{tabular}{lclccc}
\hline $\begin{array}{l}\text { Histological } \\
\text { diagnosis }\end{array}$ & $\begin{array}{l}\text { Patients } \\
(n)\end{array}$ & $\begin{array}{l}\text { Mean age } \\
(S D)\end{array}$ & $\begin{array}{l}\text { Mean no. } \\
(S D)\end{array}$ & $\begin{array}{l}\text { Patients }(n) \\
I M+(\% n)\end{array}$ & $\begin{array}{r}\text { Patients }(n) \\
\text { HP+ }(\% n)\end{array}$ \\
\hline Normal & 126 & $51 \cdot 6(17 \cdot 7)$ & $2 \cdot 9(1 \cdot 8)$ & $0(0 \%)$ & $2(1 \cdot 6 \%)$ \\
Erosion & 26 & $60 \cdot 0(15 \cdot 7)$ & $3 \cdot 2(2 \cdot 2)$ & $1(3 \cdot 9 \%)$ & $12(46 \cdot 1 \%)$ \\
Gastritis & 298 & $58 \cdot 4(16 \cdot 3)$ & $3 \cdot 6(2 \cdot 8)$ & $88(29 \cdot 5 \%)$ & $228(76 \cdot 5 \%)$ \\
Gastric ulcer & 67 & $63 \cdot 8(15 \cdot 8)$ & $8 \cdot 7(3 \cdot 8)$ & $37(55 \cdot 2 \%)$ & $47(70 \cdot 2 \%)$ \\
Gastric cancer & & & & & \\
$\quad$ Intestinal type & 8 & $77 \cdot 5(6 \cdot 5)$ & $8 \cdot 9(2 \cdot 5)$ & $8(100 \%)$ & $0(0 \%)$ \\
$\quad$ Diffuse type & 8 & $57 \cdot 9(11)$ & $12 \cdot 4(4 \cdot 1)$ & $1(12 \cdot 5 \%)$ & $0(0 \%)$ \\
& 533 & & & $135(25 \cdot 3 \%)$ & $289(54 \cdot 2 \%)$ \\
\hline
\end{tabular}

$\mathrm{IM}+=$ Intestinal metaplasia positive

$\mathrm{HP}+=H$ pylori positive.

TABLE II Prevalence of intestinal metaplasia, intestinal metaplasia subtypes and $\mathrm{H}$ pylori according to age $(\mathrm{n}=533)$

\begin{tabular}{lcccccc}
\hline $\begin{array}{l}\text { Age group } \\
(y r)\end{array}$ & $\begin{array}{l}\text { Patients } \\
(n)\end{array}$ & $\begin{array}{c}H P+p t s(n) \\
(\% n)\end{array}$ & $\begin{array}{c}I M+p t s(n) \\
(\% n)\end{array}$ & \multicolumn{2}{c}{ Percentage in IM+ patients } \\
\cline { 5 - 7 } & 2 & $0(0 \%)$ & $0(0 \%)$ & $0 \%$ & $0 \%$ & $0 \%$ \\
\hline 20 & 34 & $12(35 \cdot 3 \%)$ & $1(2 \cdot 9 \%)$ & $100 \%$ & $0 \%$ & $0 \%$ \\
$20-29$ & 41 & $21(51 \cdot 2 \%)$ & $3(7 \cdot 3 \%)$ & $100 \%$ & $66 \cdot 6 \%$ & $0 \%$ \\
$30-39$ & 86 & $43(50 \%)$ & $13(15 \cdot 1 \%)$ & $100 \%$ & $76 \cdot 9 \%$ & $7 \cdot 7 \%$ \\
$40-49$ & 106 & $69(65 \cdot 1 \%)$ & $25(23 \cdot 6 \%)$ & $100 \%$ & $76 \%$ & $8 \%$ \\
$50-59$ & 114 & $66(57 \cdot 9 \%)$ & $28(24 \cdot 6 \%)$ & $92.8 \%$ & $85 \cdot 7 \%$ & $14 \cdot 3 \%$ \\
$60-69$ & 92 & $52(56 \cdot 5 \%)$ & $38(41 \cdot 3 \%)$ & $100 \%$ & $81 \cdot 6 \%$ & $18 \cdot 4 \%$ \\
$70-79$ & 58 & $26(44 \cdot 8 \%)$ & $27(46 \cdot 6 \%)$ & $100 \%$ & $74 \cdot 1 \%$ & $22 \cdot 2 \%$ \\
$\geq 80$ & 533 & $289(54 \cdot 2 \%)$ & $135(25 \cdot 3 \%)$ & & & \\
\hline
\end{tabular}

$\mathrm{IM}+=$ Intestinal metaplasia positive.

$\mathrm{HP}+=H$ pylori positive
289 patients $(54 \cdot 2 \%)$ (Table I). In the group of 135 intestinal metaplasia positive patients, type I was found in 133 patients $(98 \cdot 5 \%)$, type II in 106 patients $(78.5 \%)$ and type III in 21 patients $(15 \cdot 6 \%)$. Ninety eight of these 135 patients $(72.6 \%)$ were $H$ pylori positive and 37 patients $(27 \cdot 4 \%)$ were $H$ pylori negative. Although the prevalence of type III intestinal metaplasia, in contrast with type I and II, increased with age, the difference in mean age between patients with type I, type II, and type III intestinal metaplasia (type I: 66 $(14 \cdot 1)$ years; type II intestinal metaplasia: $66 \cdot 5(13 \cdot 1)$ years; type III intestinal metaplasia: $71(12.9)$ years $)$ did not reach statistical significance $(0.05 p \leq 0 \cdot 1)$. For age related prevalence of intestinal metaplasia, intestinal metaplasia subtypes and $H$ pylori, see Table II.

RELATIONSHIP BETWEEN $H$ PYLORI AND SUBTYPES OF INTESTINAL METAPLASIA $(\mathrm{N}=135)$

No significant difference in prevalence of type I and II intestinal metaplasia was found between the $H$ pylori positive patients $(\mathrm{n}=98)$ and the $H$ pylori negative patients $(\mathrm{n}=37)$ - namely, type I intestinal metaplasia: 99\% (97/98) v 97.3\% (36/ $37)$ and type II $76 \cdot 5 \%(75 / 98) v 83 \cdot 9 \%$ (31/37). In contrast, the prevalence of type III was significantly lower in the $H$ pylori positive patients than in the $H$ pylori negative patients $(11 \cdot 2 \%(11 / 98) v$ $27 \%(10 / 37)-\mathrm{p}<0.05)$.

Mild intestinal metaplasia was found in 103 patients $(76.3 \%)$, moderate/severe intestinal metaplasia was found in 32 patients $(23 \cdot 7 \%)$. Although moderate/severe intestinal metaplasia was found more often in the $H$ pylori negative group (32.4\%) than in the $H$ pylori positive group $(20.4 \%)$, this difference was not statistically significant $(0 \cdot 2<\mathrm{p} \leq 0 \cdot 3)$. No significant difference was found in the prevalence of type I and II intestinal metaplasia between mild and moderate/severe intestinal metaplasia (type I: $98 \% v 100 \%$, type II: $75 \cdot 7 \% v 87 \cdot 5 \%$ ). Type III was found more often in cases of moderate/severe intestinal metaplasia $(31.3 \%)$ than in cases of mild intestinal metaplasia $(10 \cdot 7 \%)(p<0.02)$. Moreover, in the group of patients with moderate/severe intestinal metaplasia $(\mathrm{n}=32)$ type III was found more often in $H$ pylori negative patients (seven of 12 ) than in $H$ pylori positive patients (three of 20$)(\mathrm{p}<0.05)$.

\section{Discussion}

Based on observations in populations with a high risk of developing gastric carcinoma, Correa postulated that intestinal type gastric carcinoma might be the end result of a long process of sequential histological changes. It is assumed that chronic active gastritis may progress to chronic gastritis with variable degree of atrophy. On this atrophic background, intestinal metaplasia sets in and finally dysplasia and carcinoma develop. ${ }^{1819}$ The possibly precancerous nature of chronic gastritis with severe atrophy is supported by the findings of Sipponen et al. They showed that in patients with chronic antral gastritis with severe atrophy, the relative risk of gastric carcinoma is increased 18 fold. The 
cumulative cancer risk within 10 years of diagnosis was reported to be $8 \cdot 7 \%$ for the age group $50-54$ years. ${ }^{20}$

Numerous studies have emphasised the existence of an aetiopathogenetic relationship between intestinal metaplasia and intestinal type gastric carcinoma. Our finding that the majority of the patients with benign gastric ulcer were intestinal metaplasia positive is in agreement with the results reported by others. ${ }^{21} 22$ These observations clearly limit the use of intestinal metaplasia in general as an indicator of possibly increased gastric cancer risk. It has been shown, however, that sulphomucin secreting incomplete intestinal metaplasia subtype, that is, type III intestinal metaplasia, is found significantly more often in the mucosa surrounding intestinal type gastric carcinoma than in the mucosa surrounding either diffuse type carcinoma or benign gastric ulcer. ${ }^{8-1323}$ This observation not only holds true for advanced carcinomas but for early carcinomas as well. ${ }^{24}$ Additional evidence from other studies has led to the assumption that only type III intestinal metaplasia might be regarded as a marker of increased gastric cancer risk..$^{25-27}$ In this study, type III intestinal metaplasia, in contrast with type I and II, was found more often in moderate/severe intestinal metaplasia than in mild intestinal metaplasia. Moreover, the prevalence of this intestinal metaplasia subtype increased with age. Similar findings were

Figure: Hypothetical pathogenesis of intestinal type gastric carcinoma.

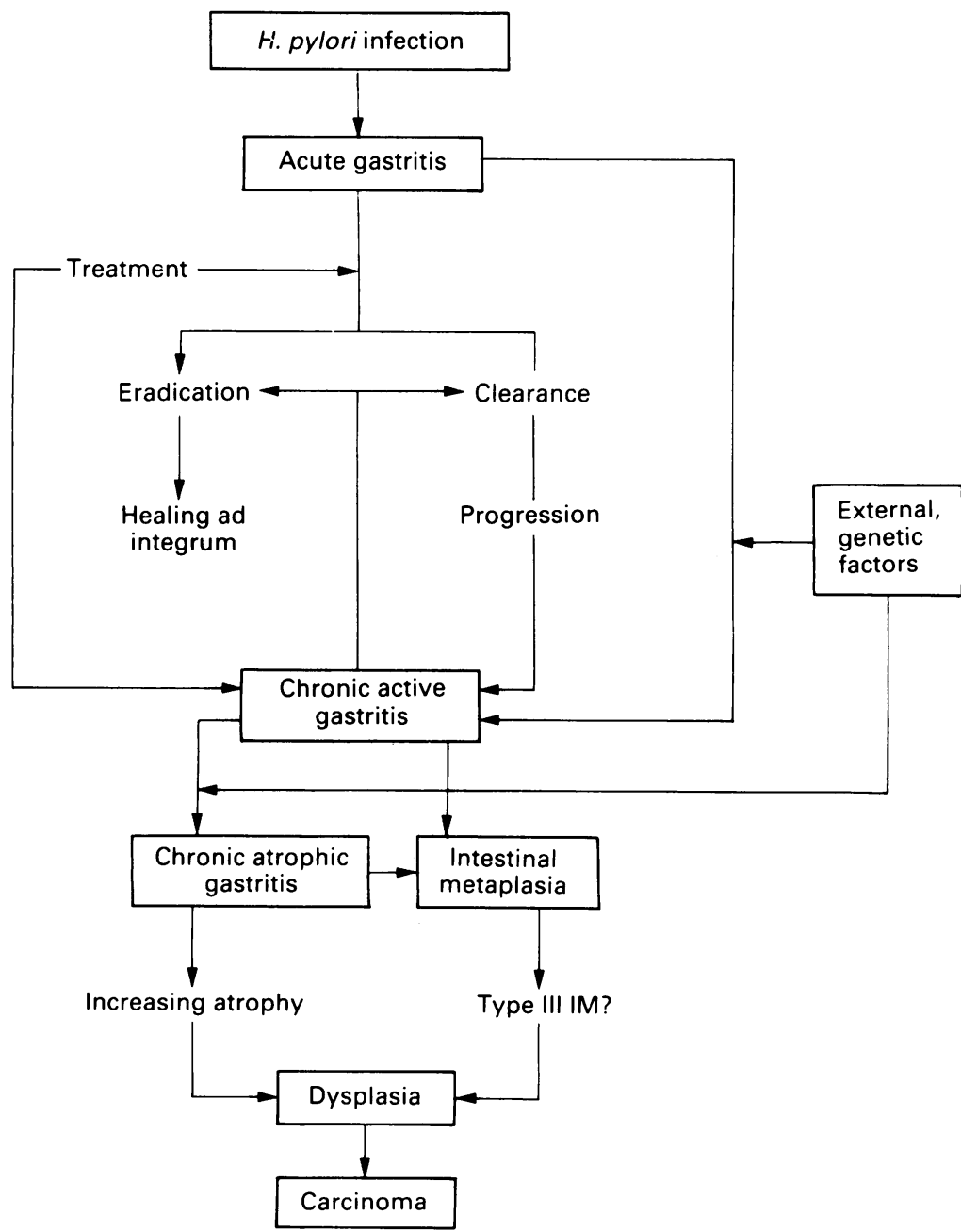

that type III intestinal metaplasia might be the result of longstanding and persistent mucosal injury. Interestingly, in a six year follow up study of subtypes of intestinal metaplasia, type III was reported to be related to prolonged injury and chronicity, to delayed ulcer healing and frequent ulcer relapse. ${ }^{28}$

At present, there is still much debate whether or not $H$ pylori and intestinal metaplasia are related. In the classifications of chronic gastritis by Whitehead, ${ }^{29}$ Cheli and Giacosa ${ }^{30}$ and Wyatt and Dixon, ${ }^{31}$ intestinal metaplasia is considered more or less a sequel to inflammation and part of a progressive process. This leaves room for the concept that intestinal metaplasia might be a result of $H$ pylori related gastritis. In contrast, Correa $^{32}{ }^{33}$ and Yardley ${ }^{34} 35$ propose that the finding of intestinal metaplasia in gastric biopsies indicate an aetiology for gastritis distinct from $H$ pylori. They suggest that intestinal metaplasia is the result of exogenous and/or dietary factors $^{3637}$ other than $H$ pylori infection. Kekki et al, however, showed in their longitudinal study that non-atrophic and non-metaplastic chronic gastritis can evolve into chronic atrophic gastritis with intestinal metaplasia. ${ }^{38}$ In an earlier study we reported that intestinal metaplasia was found more often in $H$ pylori positive patients than in negative patients. ${ }^{14}$ Therefore, because the possibility remains that $H$ pylori related chronic active gastritis may evolve into chronic gastritis with a variable degree of atrophy and intestinal metaplasia, we further investigated whether a different relationship could be found between $H$ pylori and the various intestinal metaplasia subtypes.

Type III intestinal metaplasia was found less often in $H$ pylori positive patients as compared with $H$ pylori negative patients. Although the overall degree of intestinal metaplasia in the latter two groups was not significantly different, type III intestinal metaplasia was found less often in $H$ pylori positive patients with moderate/ severe intestinal metaplasia than in $H$ pylori negative patients with moderate/severe intestinal metaplasia. These results suggest that in type III intestinal metaplasia positive patients the gastric milieu has become increasingly inhospitable for $H$ pylori. It has been reported that this intestinal metaplasia subtype was found more often in the absence of appreciable inflammation and was rarely found in severe active gastritis. ${ }^{28} \mathrm{We}$ found that the prevalence of $H$ pylori decreases in patients aged $\geq 60$ years, whereas the prevalence of intestinal metaplasia in general and subtype III in particular, increases with age. All these data further support the concept of increasing inhospitality of the gastric milieu for $\mathrm{H}$ pylori, as intestinal metaplasia represents an inhospitable site for this microorganism.

We believe that at least some of the intestinal type carcinomas might be the late result of $H$ pylori infection as depicted in the Figure. The process of gastrocarcinogenesis is multifactorial involving genetic factors and exogenous carcinogens. Recent studies have shown that the $H$ pylori serum antibody prevalence in populations with contrasting cancer risks is significantly higher in populations with a high cancer risk..$^{39+0}$ Because there are also populations with a high 
prevalence of $H$ pylori infection and a low gastric cancer risk, ${ }^{+1}$ it is clear that there must be other factors at work in the process of gastrocarcinogenesis. It may well be that $H$ pylori acts as a promotor in the latter process as suggested by Scott $e t a l^{12}$ and Correa. ${ }^{+3}$ In view of their reports, the treatment of $H$ pylori related gastritis, leading to eradication of the microorganism, might assist in removing a potential risk factor in gastric cancer prone patients. The fact that all eight patients with intestinal type carcinoma in our study were $H$ pylori negative, is not necessarily contradictory to their postulate. It could merely reflect the inhospitable milieu for $H$ pylori in these patients. It is of interest that five of these eight patients were type III intestinal metaplasia positive. ${ }^{H}$

In conclusion we believe that this is the first study addressing the distribution of intestinal metaplasia subtypes in relation to $H$ pylori. We suggest that the negative relationship between the presence of type III intestinal metaplasia and $H$ pylori is caused by the altered gastric milieu in type III intestinal metaplasia positive patients. At present, through discovery of $H$ pylori as the leading cause of gastric inflammation, much attention is directed to the long term consequences of gastric inflammation. We think that investigations should also monitor intestinal metaplasia and its subtypes in long term follow up studies with and without eradication of $H$ pylori. This might lead to a better knowledge of the mechanisms involved in the development of intestinal type carcinoma. Because no real progress has been made in the early detection of gastric carcinoma, this would be of paramount importance.

1 Warren JR, Marshall BJ. Unidentified curved bacilli on gastric epithelium in active chronic gastritis. Lancet 1983; 1273-5.

2 Blaser MJ. Gastric Campylobacter-like organism, gastritis and peptic ulcer disease. Gastroenterology 1987; 93: 371-83.

Rauws EAJ, Langenberg W, Houthoff $\mathrm{HJ}$, Zanen HC, Tytga GNJ. Campylobacter pyloridis-associated chronic active antral gastritis: a prospective study of its prevalence and the effects of anti-bacterial and anti-ulcer treatment. Gastroenterology 1988; 94: 33-40.

4 Marshall BJ, Armstrong JA, McGechie DB, Glancy RJ Attempt to fulfil Koch's postulates for pyloric Campylobacter. Med $\mathcal{F}$ A ust 1985; 142: 436-9.

5 Morris A, Nicholson G. Ingestion of Campylobacter pyloridis causes gastritis and raised fasting gastric $\mathrm{pH} . \mathrm{Am} \mathcal{f}$ Gastroenterol 1987; 82: 192-9.

6 Dooley CP, McKenna D, Humphreys H, Bourke S, Keane $\mathrm{CT}$, Sweeney $\mathrm{E}$, et al. Histological gastritis in duodenal CT, Sweeney E, et al. Histological gastris

7 Correa P. Precursors of gastric and esophageal cancer. Cancer 1982; 50: 2554-65.

8 Huang CB, Xu J, Huang JF, Meng XY. Sulphomucin colonic type intestinal metaplasia and carcinoma in the stomach. Cancer 1986; 57: 1370-5.

9 Jass JR, Filipe MI. A variant of intestinal metaplasia associated with gastric carcinoma: a histochemical study. Histopathology 1979; 3: 191-9.

10 Jass JR. Role of intestinal metaplasia in the histogenesis of gastric carcinoma. F Clin Pathol 1980; 33: 801-10.

11 Jass JR, Filipe MI. The mucin profiles of normal gastric mucosa, intestinal metaplasia and its variants and gastric carcinoma. Histochem f 1981; 13: 931-9.

12 Segura DI, Montero C. Histochemical characterization of different types of intestinal metaplasia in gastric mucosa. different types of intestin.

13 Heilmann KL, Hopker WW. Loss of differentiation in intestinal metaplasia in cancerous stomachs. A comparative morphologic study. Pathol Res Pract 1979; 164: 249-58.

14 Craanen ME, Dekker W, Blok P, Ferwerda J, Tytgat GNJ Intestinal metaplasia and Helicobacter pylori: an endoscopic-bioptic study of the gastric antrum Gut 1992 33: 16-20.

15 Mowry RW. The special value of methods that color both acidic and vicinal hydroxyl groups in the histochemical study of mucins: with revised directions for the colloidal iron stain, the use of alcian blue $8 \mathrm{GX}$ and their combinations with the PAS reaction. Ann NY Acad Sci 1963; 106: 402-23.

16 Spicer SS. Diamine methods for differentiating mucosubstances histochemically. $\mathcal{F}$ Histochem Cytochem 1965; 13: 211-34.

17 Filipe MI. Histochemistry of intestinal mucins. In: Whitehead $\mathrm{R}$, ed. Gastrointestinal and oesophageal pathology. 1st ed, Edinburgh: Churchill Livingstone, 1989: 71 .

18 Correa P, Cuello C, Duque E, Burbano LC, Garcia FC, Bolanos $\mathrm{O}$, et al. Gastric cancer in Columbia. III. Natural history of precursor lesions. 7 Natl Cancer Inst 1976; 57 : 1027-35.

19 Correa P. A human model of gastric carcinogenesis. Cancer Res 1988; 48: 1319-26.

20 Sipponen P, Kekki M, Haapakoski J, Ihamaki T, Siurala M. Gastric cancer risk in chronic atrophic gastritis: statistical Gastric cancer risk in chronic atrophic gastritis: statistical calculation.

21 Stemmermann GN, Hayashi T. Intestinal metaplasia of the gastric mucosa: a gross and microscopic study of its distribution in various disease states. $\mathcal{F}$ Natl Cancer Inst 1968; 41: 627-34.

22 Meister H, Holubarsch CH, Haferkamp O, Schlag P. Gastritis, intestinal metaplasia and dysplasia versus benign ulcer in stomach and duodenum and gastric carcinoma: A histoin stomach and duodenum and gastric carcinoma: A hical study. Pathol Res Pract 1979; 164: 256-69.

23 Filipe MI, Potet F, Bogomoletz WV, Dawson PA, Fabiani B, Chauveinc $\mathrm{P}$, et al. Incomplete sulphomucin-secreting intestinal metaplasia for gastric cancer. Preliminary data intestinal metaplasia for gastric cancer. Preliminary data from a prosp

24 Hirota $T$, Okada T, Itabashi M, Yoshida H, Matsukura N, Kitaoka $\mathrm{H}$, et al. Significance of intestinal metaplasia as a precancerous condition of the stomach. In: Ming SC, ed. Precursors of gastric cancer. New York: Praeger Publications, 1984: 179-93.

25 Jass JR, Filipe MI. Sulphomucins and precancerous lesions of the human stomach. Histopathology 1980; 4: 271-9.

26 Day DW, Morson BC. Gastric cancer. In: Anthony PP, Wool $\mathrm{N}$, eds. Recent advances in histopathology. Edinburgh: Churchill Livingstone, 1978; 10: 159-78.

27 Sipponen P, Seppala K, Varis K, Hjelt L, Ihamaki T, Kekk $\mathrm{M}$, et al. Intestinal metaplasia with colonic-type sulphomucins in the gastric mucosa; its association with gastric mucins in the gastric mucosa; its association with gastric

28 Silva S, Filipe MI, Pinho A. Variants of intestinal metaplasia in the evolution of chronic atrophic gastritis and gastric ulcer. A follow up study. Gut 1990; 31: 1097-105.

29 Whitehead R, Truelove SC, Gear MWL. The histological diagnosis of chronic gastritis in fibreoptic gastroscope biopsy specimens. F Clin Pathol 1972; 25: 1-11

30 Cheli R, Giacosa A. Chronic atrophic gastritis and gastric mucosal atrophy - one and the same. Gastrointest Endosc 1983; 29: 23-5

31 Wyatt JL, Dixon MF. Chronic gastritis - a pathogenetic approach. F pathol 1988; 154: 113-24.

32 Correa P. The epidemiology and pathogenesis of chronic gastritis: three etiologic entities. Front Gastrointest Res 1980 6: $98-108$.

33 Correa P. Chronic gastritis: A clinico-pathological classification. Am $\mathcal{F}$ Gastroenterol 1988; 83: 504-9.

34 Paull G, Yardley JM. Pathology of C. pylori-associated gastric and esophageal lesions. In: Blaser MJ, ed. Campylobacter pylori in gastritis and peptic ulcer disease. New York: IgakuShoin, 1989: 73-97.

35 Yardley JH. Pathology of chronic gastritis and duodenitis. In Goldman H, Appelman HD, eds. Gastrointestinal pathology. Baltimore: Williams and Wilkins, 1990: 69-143.

36 Nomura A, Yamakawa H, Ishidate, T, Kamiyama S, Masuda $\mathrm{H}$, Stemmermann GN, et al. Intestinal metaplasia in Japan Association with diet. F Natl Cancer Inst 1982; 68: 401-5.

37 Fontham E, Zavala D, Correa P, Rodriguez E, Hunter F, Haenszel W, et al. Diet and chronic atrophic gastritis: A case-control study. F Natl Cancer Inst 1986; 76: 621-7.

38 Kekki M, Siurala M, Varis K, Sipponen P, Sistonen P, Nevanlinna RH. Classification principles and genetics of Nevanlinna RH. Classification principles and genetics of chron.

39 Correa P, Fox J, Fontham E, Ruiz B, Lin Y, Zavala D, et al. Helicobacter pylori and gastric carcinoma. Cancer 1990; 66 : 2569-74.

40 Sitas F, Forman D, Yarnell JWG, Burr ML, Elwood PC Pedley $\mathrm{S}$, et al. Helicobacter pylori infection rates in relation to age and social class in a population of Welsh men. Gu 1991; 32: 25-8

41 Olive C, Michault A, Brassens-Rabbe MP, Megraud F. Seroepidemiology of Campylobacter pylori in Reunion Island. Klin Wochenschr 1989; 67: 52. [Abstract]

42 Scott N, Lansdown M, Diament R, Rathbone B, Murday V, Wyatt JI, et al. Helicobacter gastritis and intestinal metaplasia in a gastric cancer family. (Letter) Lancet 1990; 335: 728.

43 Correa P, Ruiz B. Campylobacter pylori and gastric cancer. In Rathbone BJ, Heatley RV, eds. Campylobacter pvlori and Rathbone BJ, Heatley RV, eds. Campvlobacter pvlon and
gastroduodenal disease. Oxford: Blackwell Scientific, 1989; gastroduod

44 Craanen ME, Blok P, Dekker W, Ferwerda J, Tytgat GNJ Prevalence of subtypes of intestinal metaplasia in gastric antral mucosa. Dig Dis Sci 1991; 36: 1529-36. 